\title{
The effect of stimulants on irritability in autism comorbid with ADHD: a systematic review
}

This article was published in the following Dove Press journal:

Neuropsychiatric Disease and Treatment

\author{
Ahmad Ghanizadeh ${ }^{1,2}$ \\ Mohammed Molla ${ }^{2}$ \\ Garth Jon Olango 2
}

'Research Center for Psychiatry and Behavioral Sciences, Department of Psychiatry, Shiraz University of Medical Sciences, Shiraz, Iran; ${ }^{2}$ Department of Psychiatry, UCLA-Kern Psychiatry Residency Program, Kern Medical, Kern Behavioral Health and Recovery Services, Bakersfield, CA, USA
Correspondence: Ahmad Ghanizadeh Department of Psychiatry, Hafez hospital, Shiraz University of Medical Sciences, Shiraz, Iran

Tel +987136479080

Email ghanizadeha@hotmail.com
Introduction: While there is a very high rate of comorbidity of autism and ADHD, there are controversies about prescribing stimulants in children with autism. This is a systematic review about the effect of stimulants on irritability in children with both autism and ADHD. Methods: A systematic review was conducted to study the possible effect of stimulants on irritability in autism and ADHD using the databases of PubMed, Scopus, EMBASE, and ScienceDirect in September 2018. Eligible clinical trials of stimulants in the treatment of Autism and ADHD without restriction of language were included. The primary outcome was irritability score. The full texts of relevant articles were studied, and their references were scanned for any possible related article.

Results: Out of 1,315 citations, there were 26 relevant articles. Of the relevant articles, 16 were not interventional studies and were excluded. There were 10 interventional studies. None of them considered irritability as a main outcome. Also, none of them studied the effect of stimulants on irritability in autism plus ADHD. Current uncontrolled evidence about the association of stimulants with irritability is controversial.

Conclusion: The current evidence is not enough to support or discourage the effect of stimulants on irritability in children and adolescents with both autism and ADHD. Welldesigned controlled clinical trials need to be conducted for this ignored research area.

Keywords: autistic disorder, attention deficit disorder with hyperactivity, central nervous system stimulants, irritable mood, comorbidity, methylphenidate

\section{Introduction}

\section{Irritability}

Irritability or severe mood dysregulation, ${ }^{1}$ which is very common in both attention deficit hyperactivity disorder (ADHD) and autism, is not a diagnostic criterion or symptom of either autism or ADHD. The rate of irritability in a clinical sample of 696 children (mean age $=10.9$ years) with ADHD was very high. About $91 \%$ of them were with at least an irritability symptom. Higher levels of irritability are associated with a higher rate of comorbidity with symptoms of anxiety and depression. ${ }^{2}$ Irritability is also related to the outcome of ADHD. For example, anger-irritability in children with ADHD was a mediator for drinking outcomes in adolescence. $^{3}$

\section{Treatment of irritability in ADHD}

Stimulants usually improve irritability in ADHD. Aripiprazole/methylphenidate combination significantly improves irritability in children with disruptive mood dysregulation disorder (DMDD) and ADHD. The effect sizes of reductions in 
parent-rated irritability was Cohen's $\mathrm{d}=1.26 .{ }^{4} \mathrm{MPH}$ improves both ADHD and DMDD symptoms. Its effect on irritability is mixed. It improved irritability in $71 \%$, but worsened it in $19 \%$, and caused no change in $10 \%$ of the patients. ${ }^{5}$

\section{Stimulants and irritability}

Emotion dysregulation (irritability) is very common in children with ADHD. It is reported up to $25-45 \%{ }^{6}$ While amphetamine-derived psychostimulants increase irritability, methylphenidate (MPH) derivatives significantly decrease the risk of irritability in comparison to placebo. $^{7}$ However, head-to-head comparison trials between methylphenidate and amphetamine derivatives to examine their effects on irritability is recommended. Lisdexamfetamine dimesylate (LDX) caused irritability in $8.6 \%$ of children and adolescents with ADHD. ${ }^{8}$

Chewable methylphenidate extended-release in children with ADHD induced irritability in $13.3 \%$ of patients. This was one of the most common adverse effects. ${ }^{9}$ Another study reported a rate of $16 \%{ }^{10}$ The rate for irritability in an extended-release oral MPH in ADHD children in a laboratory classroom setting was $6.9 \%{ }^{11}$

On the other hand, stimulants are superior to behavioral management for treating irritability in ADHD. ${ }^{12}$ Irritability does not moderate the effect of treatment of ADHD symptoms. ${ }^{12}$ Therefore, it is suggested that treating ADHD symptoms improves irritability in ADHD. ${ }^{12}$

\section{ADHD in autism}

Comorbidity of ADHD with autism is very common. In a chart retrospective study of 27 patients with pervasive developmental disorder (PDD), 26\% were with the Combined type of ADHD, 33\% with the Inattentive type of ADHD and $41 \%$ were without ADHD. ${ }^{13}$ Another study included a clinical sample of 68 children with PDD, and reported that the rate of ADHD comorbidity was 53.8\%. It was $37.1 \%, 22.9 \%$, and $40.0 \%$ for Inattentive type, Hyperactivity/Impulsivity type, and Combined type; respectively. ${ }^{14}$ The rate of $78 \%$ is also reported for ADHD in autism spectrum disorders (ASD). ${ }^{15}$

\section{Stimulants in autism}

Several years ago, it was reported that amphetamine in children with PDD increased irritability rate. ${ }^{16}$ Even the use of stimulants in autism has been discouraged ${ }^{17}$ or the lower doses of stimulants in autism has been suggested. ${ }^{18}$ In addition, there are some reports that stimulants are ineffective and poorly tolerated in autism. ${ }^{19}$ The response may differ with PDD subtype. In contrast, psychostimulants are commonly prescribed for ADHD in autism. About $52.4 \%$ of children with autism received it for about 4.0 years with a favorable responses rate of $69.4 \%$. The rate of adverse effects was $16.8 \%$. About $66 \%$ of these patients experienced at least one adverse effect. ${ }^{20}$ The response rate of ADHD to stimulants in PDD is less than those without $\mathrm{PDD}^{21}$ Moreover, the rate of severe adverse effects leading to discontinuation of stimulant in ADHD plus PDD is more than those without $\mathrm{PDD}^{21}$ In contrast, others reported that the response rate of ADHD symptoms to stimulants in ADHD+autism is not different from those with ADHD alone. ${ }^{22}$

Irritability may interfere with development, social functioning, relationships, and educational functioning of children. There are different medications for the management of irritability in autism, such as aripiprazole, ${ }^{23,24}$ risperidone, ${ }^{25}$ and buspirone. ${ }^{26}$ However, there are a considerable risk of serious adverse effects, such as metabolic syndrome. Examining the association of irritability and stimulants in ADHD+autism is highly needed because there is a high rate of ADHD comorbidity with autism, and a high rate of irritability in both disorders, and some previous contradictory reports have raised serious concerns for using stimulants in ADHD+autism.

This is a systematic review studying how stimulants affect irritability in children and adolescents with autism and ADHD.

\section{Method}

\section{Data sources}

The databases of Scopus, PubMed, EMBAS, and ScienceDirect were used to search relevant articles. There was no time or language limitation for this search. The studies were on humans. The references of relevant clinical articles were examined to find any other related articles. All types of clinical trials of autism were eligible for the current search.

\section{Types of articles}

Any clinical trials related to irritability in individuals with autism diagnosis taking stimulants was examined in this review.

\section{Types of participants}

Individuals with autism spectrum disorders from all age groups were participants of this review. 


\section{Interventions type}

Monotherapy or adjuvant therapy with stimulants without considering its dosage and duration was included.

\section{Outcome measures}

Reported irritability score using any standardized irritability rating scale or autism rating scales such as the Aberrant Behavior Checklist-irritability subscale (ABC). In order to increase the sensitivity of our search for finding relevant articles, we relaxed the emphasis on irritability outcome and did not exclude those trials which reported irritability as an adverse effect.

\section{Searches}

In order to identify relevant trials, the following search strategy was used for all the databases: "autism" OR "pervasive developmental disorders" OR "autism spectrum disorders" OR "autistic disorder" AND "Ritalin" OR "methylphenidate" OR "dexamphetamine" OR "stimulants" OR "lisdexamfetamine" OR “Aderall” AND "irritability".

\section{Selection of studies}

All the titles retrieved from the databases using the abovementioned search strategies were reviewed by at least two reviewers (AG, MM, and GO). The full text of the relevant abstracts was studied by the reviewers independently. For any disputes for relevancy of articles, a discussion meeting was set to reach a consensus. Letters, abstracts, editorials, notes, book chapters, and secondary or non-interventional reviews were excluded.

So, any contributions was included if: a) its subjects were patients with autism and ADHD, b) they received the stimulants, and c) irritability was considered as an outcome or adverse effect.

\section{Results}

The search of the databases showed that there were 1,341 citations including PubMed=38, EMBASE=206, SCOPUS $=184$, and Science Direct=1,097. The duplicated articles were deleted. So, the number of remaining titles was 1,315 . Then, the titles of these 1,315 citations were studied. The references of relevant articles were scanned as well. There were only 26 relevant articles, so the remainder were eliminated for irrelevancy (Figure 1).

Of the relevant articles, 16 were not interventional studies and were excluded. ${ }^{18,27-41}$ There were 10 interventional studies. An in-depth review showed that one of the trial was the comparison of genotype of children with autism and hyperactivity in response to $\mathrm{MPH}^{42}$ Therefore, it was removed. Another one was a medical records review of 124 children with autism. ${ }^{20}$ They did not find any association between the type of stimulants and the episodes of irritability (Table 1). Another randomized clinical trial was excluded because it did not report the impact of MPH on irritability. Irritability was not examined in the subjects. ${ }^{43}$ Another trial which was excluded was a crossover trial of placebo and MPH. In this trial, irritability was not an outcome and it had not been examined. ${ }^{44}$ One study was excluded because it was a case study. ${ }^{45}$

Two trials were pilot studies. One of them was an open label trial with a small number of patients. ${ }^{46}$ This trial included 13 children with pervasive developmental disorder and hyperactivity. Irritability was not considered as an outcome measure. However, they reported that there has not been any remarkable adverse effects. It was not clear if they had checked irritability. ${ }^{46}$ One trial was without a placebocontrolled group. However, the patients were randomized to different dose titration for MPH. This showed that a low dosage of MPH did not increase irritability. However, a moderate dosage of long-acting liquid MPH increased irritability. ${ }^{47}$

So, there were only three randomized controlled clinical trials (RCT) reporting irritability in patients with autism and hyperactivity (Table 2). The outcome measure in one of the three RCTs was the ABC hyperactivity subscale. ${ }^{21}$ Patients were enrolled if they had a score of $\geq 15$ on the ADHD subscale without the necessity to have inattentiveness. So, hyperactivity was assessed rather than ADHD. Therefore, this trial was not included as well.

Another trial which was a double-blind placebo controlled crossover trial examined the impact of MPH on hyperactivity in autism. ${ }^{48}$ This small trial used Conner's Hyperactivity Index to measure hyperactivity. ADHD as a diagnosis was not considered in this trial too. The same as most of the other trials, this study also included the small sample of 13 children.

The other trial included 10 children with a DSM-III-R diagnosis of autism in a crossover study. It examined the effect of MPH on hyperactivity, not ADHD, in autism. However, irritability was checked using the ABCirritability subscale. $^{49}$

\section{Discussion}

The main aim of this systematic review was to study the association of stimulants and irritability in children and 


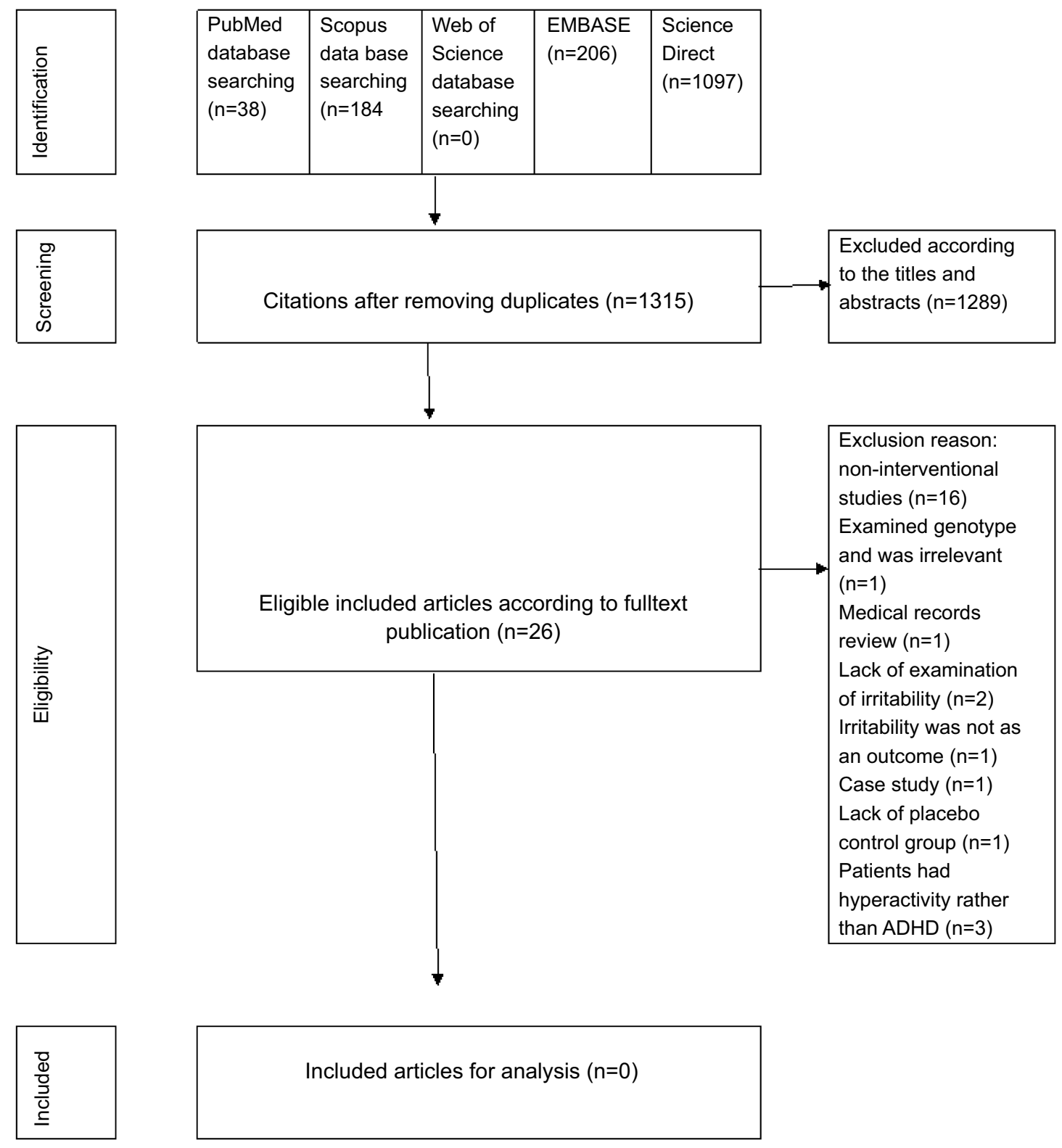

Figure I PRISMA flow chart.

adolescents with both autism and ADHD. Of the 26 relevant contributions, none of them were randomized controlled clinical trials with a considerable sample size. In addition, irritability was not a main outcome of the trials in their planning. So, in our discussion, we discuss trials that reported irritability as an adverse effect as well as to provide a comprehensive evaluation of the current evidence. To the best of our knowledge, this is the first systematic review examining the impact of stimulants on the irritability in autism comorbid with ADHD.

Generally, the rate of irritability related to stimulants was not high. A possible explanation for the low rate of irritability due to stimulants in autism is that they concurrently receive antipsychotics causing a protection from some adverse effects such as irritability. ${ }^{21}$ There are some reports that some adverse effect of stimulants might be decreased when the patient had been taking an antipsychotic before starting stimulants. ${ }^{19}$ The rate of psychostimulant prescription in autism is very high and the majority of them benefit for these medications supporting their possible remarkable role in the treatment of ADHD symptoms in autism.

Meanwhile, limited current evidence and lack of any replication of the current evidence are other issues for the generalization of the results. Previous trials did not prescribe enough high doses of stimulants for treating even 
Table I The characteristics of excluded trials

\begin{tabular}{|c|c|c|c|}
\hline Authors & Year & Methods & Reasons of exclusion and/or findings \\
\hline McCracken et. al ${ }^{42}$ & 2014 & $\begin{array}{l}\text { - Genotype data of } 64 \text { children with ASD and hyper- } \\
\text { activity who were exposed to MPH were compared }\end{array}$ & $\begin{array}{l}\text { - Irritability was not reported as an outcome } \\
\text { - Excluded from review }\end{array}$ \\
\hline Nickels et. al ${ }^{20}$ & 2008 & $\begin{array}{l}\text { - Medical review of } 124 \text { children with "research- } \\
\text { identified" autism among Olmsted County residents, } \\
\text { ages 0-2I years, in the years 1976-1997 }\end{array}$ & $\begin{array}{l}\text { - At least one side-effect in } 66 \% \text { of patients who } \\
\text { received stimulants } \\
\text { - A trend for boys more than girls for a side-effect } \\
\text { - No association between the type of psychostimulant } \\
\text { treatment (ie, dextroamphetamine or methylpheni- } \\
\text { date) and the occurrence of side-effects } \\
\text { - Ten episodes in nine different children who experi- } \\
\text { enced irritability/anxiousness/worsening of behavior } \\
\text { with methylphenidate } \\
\text { - Ten episodes in } 10 \text { different children who experienced } \\
\text { irritability/anxiousness/worsening of behavior with } \\
\text { dextroamphetamine } \\
\text { - Three episodes of irritability/anxiousness/worsening of } \\
\text { behavior with mixed amphetamine salts }\end{array}$ \\
\hline Poseny et $\mathrm{al}^{43}$ & 2007 & $\begin{array}{l}\text { - Sixty-six children (mean age } 7.5 \text { years) with autistic } \\
\text { disorder, Asperger's disorder, and PDD not otherwise } \\
\text { specified } \\
\text { - Randomized to varying sequences of placebo and } \\
\text { three different doses of methylphenidate for } \\
\text { a 4-week blinded, crossover study } \\
\text { - Methylphenidate doses used approximated } 0.125 \text {, } \\
0.25 \text {, and } 0.5 \mathrm{mg} / \mathrm{kg} \text { per dose, twice daily, with an } \\
\text { additional half-dose in the late afternoon }\end{array}$ & $\begin{array}{l}\text { - It did not report if the effect of MPH on irritability was } \\
\text { examined. Moreover, the adverse effects were not } \\
\text { reported }\end{array}$ \\
\hline Jahromi et al ${ }^{44}$ & 2009 & $\begin{array}{l}\text { - } 33 \text { children aged } 5 \text { to } 13 \text { years old } \\
\text { - A } 4 \text {-week crossover trial of placebo and increasing } \\
\text { doses of methylphenidate given in random order, each } \\
\text { for I week }\end{array}$ & $\begin{array}{l}\text { - It did not report if the effect of MPH on irritability was } \\
\text { examined. Moreover, the adverse effects were not } \\
\text { reported }\end{array}$ \\
\hline Birmaher et al ${ }^{45}$ & 1988 & - Case study & - \\
\hline Di Martino et $\mathrm{al}^{46}$ & 2004 & $\begin{array}{l}\text { - Open-label pilot trial including I3 children with PDD } \\
\text { and moderate-to-severe hyperactivity/impulsivity } \\
\text { - Symptoms assessment using Clinical Global } \\
\text { Impression (CGI), Childhood Autism, Child } \\
\text { Psychiatric and Conners Parent and Teacher Rating } \\
\text { Scales (CPRS) } \\
\text { - Assessment at baseline, and after I and } 3 \text { months of } \\
\text { treatment }\end{array}$ & $\begin{array}{l}\text { - An hour after a single MPH dose }(0.4 \mathrm{mg} / \mathrm{kg}) \text {, five } \\
\text { children showed increased hyperactivity, stereotypes, } \\
\text { dysphoria, or motor tics. There was a high rate of } \\
\text { adverse effects } \\
\text { - Four of the remaining children were rated as } \\
\text { improved, and four as unchanged } \\
\text { - There was no remarkable adverse effect in the remain- } \\
\text { ing children }\end{array}$ \\
\hline
\end{tabular}

Abbreviations: ASD, Autism Spectrum Disorders; MPH, Methylphenidate: PDD, Pervasive developmental Disorders.

hyperactivity. Maybe their concern of the unfavorable reports about using stimulants in autism had discouraged them to give enough stimulants dosage.

The nature of a symptom such as hyperactivity is different from a disorder such as ADHD. For treating ADHD, enough dosages of medications are needed. This issue should be considered in interpretation of low rate of irritability in children with autism and hyperactivity treated with stimulants. This assumption is supported by the high rate of adverse effect reported in those taking low doses of $\mathrm{MPH}^{21}$ That trial excluded the patients who reported adverse effects on the test-dose phase. It means that those who showed adverse effect in test-dose phase were not included in the trial. So, the low rate of irritability cannot be guaranteed to generalize even to all children with autism and hyperactivity. It is worthy to mention that 
Table 2 Trials examined the effect of stimulants on hyperactivity in autism and reported irritability

\begin{tabular}{|c|c|c|c|}
\hline Authors & Year & Methods & Findings \\
\hline $\begin{array}{l}\text { Research Units on } \\
\text { Pediatric } \\
\text { Psychopharmacology } \\
\text { Autism Network et } \text { al }^{21}\end{array}$ & 2005 & $\begin{array}{l}\text { - Double-blind, placebo-controlled, crossover trial } \\
\text { followed by open-label continuation } \\
72 \text { drug-free clinical sample children, aged 5-I4 } \\
\text { years, with pervasive developmental disorders } \\
\text { accompanied by moderate-to-severe hyperactivity } \\
\text { - Increasing doses of methylphenidate (low, medium, } \\
\text { and high doses) ranging from } 7.5 \mathrm{mg} / \text { day to } 50.0 \mathrm{mg} / \\
\text { day in divided doses } \\
\text { - Subjects who tolerated the test dose }(\mathrm{n}=66) \text { were } \\
\text { assigned to receive placebo for I week and then } \\
\text { three methylphenidate doses } \\
\text { - Children responding to methylphenidate then } \\
\text { entered } 8 \text { weeks of open-label treatment at the } \\
\text { individually determined best dose }\end{array}$ & $\begin{array}{l}\text { - Methylphenidate improved hyperactivity more } \\
\text { than placebo } \\
\text { - Methylphenidate respondent rate was } 49 \% \text { for } \\
\text { hyperactivity. } \\
\text { - Methylphenidate did not improved irritability } \\
\text { - I } 8 \% \text { of subjects exited the study due to intoler- } \\
\text { able adverse effects and the rate for irritability } \\
\text { was } 8.3 \% \\
\text { - The rates of irritability for low, medium, and high } \\
\text { dosages was } 7.6 \%, 12.1 \% \text {, and } 10.0 \% \text {, respectively }\end{array}$ \\
\hline Handen et $\mathrm{al}^{48}$ & 2000 & $\begin{array}{l}\text { - Thirteen children aged } 5.6-11.2 \text { years with autism } \\
\text { and ADHD symptoms } \\
\text { - Double-blind, placebo-controlled crossover study } \\
\text { of methylphenidate ( } 0.3 \text { and } 0.6 \mathrm{mg} / \mathrm{kg} \text { per dose) }\end{array}$ & $\begin{array}{l}\text { - Eight subjects responded positively with } \\
\text { a minimum } 50 \% \text { decrease in Hyperactivity Index } \\
\text { - Irritability was among significant adverse side- } \\
\text { effects. However, its mean score was less than } \\
\text { that of placebo. The percentage of irritability } \\
\text { with higher doses was } 70 \% \text {, while in the placebo } \\
\text { group it was } 63.3 \%\end{array}$ \\
\hline Quintana et $\mathrm{al}^{49}$ & 1995 & $\begin{array}{l}\text { - Methylphenidate (MPH) for the treatment of } \\
\text { selected symptoms of autistic disorder } \\
\text { - double-blind crossover study using placebo and two } \\
\text { MPH doses ( } 10 \mathrm{mg} \text { or } 20 \mathrm{mg} \text { bid) } \\
\text { - I0 children, ages 7-II, with a DSM-III-R diagnosis } \\
\text { of autistic disorder }\end{array}$ & $\begin{array}{l}\text { - Statistically significant improvement on } \mathrm{MPH} \\
\text { over placebo for hyperactivity } \\
\text { - Irritability in } 4 \% \text { patients with high dose of } \mathrm{MPH} \\
(20 \mathrm{mg}) \\
\text { - Lack of worsening or serious adverse effect } \\
\text { including irritability } \\
\text { - The irritability score of } \mathrm{ABC} \text { decreased from } \\
\text { II.8 to } 4.0(P<0.0 \mathrm{I}) \text {. }\end{array}$ \\
\hline Kim et $\mathrm{a}^{47}$ & 2017 & $\begin{array}{l}\text { - } 27 \text { children with autism and ADHD were rando- } \\
\text { mized to different dose titration schedules of long- } \\
\text { acting liquid methylphenidate (MPH) for } 6 \text { weeks } \\
\text { - Aberrant behavior checklist (ABC) was used to } \\
\text { check irritability }\end{array}$ & $\begin{array}{l}\text { - Low-to-moderate doses of MPH was effective in } \\
\text { reducing ADHD symptoms and it was tolerated } \\
\text { well } \\
\text { - Low dose of MPH did not increase irritability } \\
\text { score } \\
\text { - Moderate dose of MPH significantly decreased } \\
\text { irritability score }\end{array}$ \\
\hline
\end{tabular}

Abbreviations: ADHD, Attention Deficit Hyperactivity Disorder; MPH, Methylphenidate.

even a low dose in those who did not show an adverse effect in test-dose phase had a high rate of severe adverse effects leading to a discontinuation of the medication. ${ }^{21}$

Stimulants are a group of medications such as MPH and dextroamphetamin. There are some long acting stimulants. There is no evidence if the efficacy of the different types of stimulants on ADHD symptoms or their adverse effects including irritability are different.

Autism is not a homogenous disorder, and it is usually comorbid with some cognitive dysfunctions or mental disability. Therefore, mental disability is another covariant factor. This issue and its effect on response to medications and adverse effects needs to be considered.

All the current trials administered stimulants for relatively short periods. Meanwhile, ADHD needs long-term treatment with stimulants. It is not known whether the impact of stimulants on irritability in autism and ADHD in the short-term is the same as long-term use. Furthermore, ADHD is not just hyperactivity. Additionally, there are different types of ADHD, including Hyperactive-impulsive type, Inattentive type, and Combined type. 
Well controlled trials with enrollment of children and adolescents with a DSM diagnosis of autism and ADHD were not found. Since there are some reports discouraging prescribing stimulants for treating ADHD plus autism, well controlled trials with enough sample size using DSM diagnostic criteria for ADHD and enough dosage of stimulants are needed to examine the impact of therapeutic dosage of stimulants on irritability in ADHD and autism. Irritability should be checked using standard instruments as well. Some studies just reported irritability as an adverse effect, while some others used questioners such as the ABC-irritability subscale. Further studies should consider irritability as a main outcome, and it needs to be assessed by standard instruments.

Possible withdrawal after discontinuation of stimulants in autism plus ADHD needs to be considered. So, the measurement of irritability after discontinuation of the medication should be done. Moreover, it is not clear whether there is any difference between the effect of short-acting vs long-acting stimulants on irritability in ADHD plus autism. Of course, before that, a clear operationalized definition of irritability is needed. The concomitant use of other medications including neuroleptic medication needs to be considered. Finally, the comorbidities of psychiatric disorders in both ADHD and autism is common. Future clinical trials should consider these comorbidities, such as oppositional defiant disorder and conduct disorder.

Some studies were retrospective. So, there is a high chance of ignoring or lack of detections of some symptoms or adverse effects such as irritability or even incomplete documentations of adverse effects leading to missing some information. Even those trials which were randomized controlled trials had not originally been designed to assess irritability in children with autism, leading to a lack of stratification of randomization for the patients with irritability status.

\section{Conclusion}

For the studies discussed above, there is not enough evidence to support or discourage the effect of stimulants on irritability in children and adolescents with both autism and ADHD.

\section{Disclosure}

The authors report no conflicts of interest in this work.

\section{References}

1. Leibenluft E. Severe mood dysregulation, irritability, and the diagnostic boundaries of bipolar disorder in youths. Am J Psychiatry. 2011;168:129-142. doi:10.1176/appi.ajp.2010.10050766

2. Eyre O, Langley K, Stringaris A, Leibenluft E, Collishaw S, Thapar A. Irritability in ADHD: associations with depression liability. $J$ Affect Disord. 2017;215:281-287. doi:10.1016/j. jad.2017.03.050

3. Harty SC, Gnagy EM, Pelham WE Jr., Molina BSG. Anger-irritability as a mediator of attention deficit hyperactivity disorder risk for adolescent alcohol use and the contribution of coping skills. $J$ Child Psychol Psychiatry. 2017;58:555-563. doi:10.1111/jcpp.12668

4. Pan PY, Fu AT, Yeh CB. Aripiprazole/methylphenidate combination in children and adolescents with disruptive mood dysregulation disorder and attention-deficit/hyperactivity disorder: an open-label study. $J$ Child Adolesc Psychopharmacol. 2018;28:682-689. doi:10.1089/ cap.2018.0068

5. Winters DE, Fukui S, Leibenluft E, Hulvershorn LA. Improvements in Irritability with open-label methylphenidate treatment in youth with comorbid attention deficit/hyperactivity disorder and disruptive mood dysregulation disorder. $J$ Child Adolesc Psychopharmacol. 2018;28:298-305. doi:10.1089/cap.2017.0124

6. Shaw P, Stringaris A, Nigg J, Leibenluft E. Emotion dysregulation in attention deficit hyperactivity disorder. $A m \quad J$ Psychiatry. 2014;171:276-293. doi:10.1176/appi.ajp.2013.13070966

7. Stuckelman ZD, Mulqueen JM, Ferracioli-Oda E, et al. Risk of irritability with psychostimulant treatment in children with ADHD: a meta-analysis. J Clin Psychiatry. 2017;78:e648-e655. doi:10.4088/JCP.15r10601

8. Coghill DR, Banaschewski T, Nagy P, et al. Long-term safety and efficacy of lisdexamfetamine dimesylate in children and adolescents with ADHD: a phase IV, 2-Year, open-label study in Europe. CNS Drugs. 2017;31:625-638. doi:10.1007/s40263-017-0443-y

9. Wigal SB, Childress A, Berry SA, et al. Efficacy and safety of a chewable methylphenidate extended-release tablet in children with attention-deficit/hyperactivity disorder. $J$ Child Adolesc Psychopharmacol. 2017;27:690-699. doi:10.1089/cap.2016.0177

10. Wigal SB, Kollins SH, Childress AC, Squires L, Study G. A 13 hour laboratory school study of lisdexamfetamine dimesylate in school-aged children with attention-deficit/hyperactivity disorder. Child Adolesc Psychiatry Ment Health. 2009;3:17. doi:10.1186/1753-2000-3-17

11. Childress AC, Kollins SH, Cutler AJ, Marraffino A, Sikes CR. Efficacy, safety, and tolerability of an extended-release orally disintegrating methylphenidate tablet in children 6-12 years of age with attention-deficit/hyperactivity disorder in the laboratory classroom setting. $J$ Child Adolesc Psychopharmacol. 2017;27:66-74. doi:10.1089/cap.2016.0002

12. Fernandez de la Cruz L, Simonoff E, McGough JJ, Halperin JM, Arnold LE, Stringaris A. Treatment of children with attention-deficit/ hyperactivity disorder (ADHD) and irritability: results from the multimodal treatment study of children with ADHD (MTA). $J$ Am Acad Child Adolesc Psychiatry. 2015;54:62-70.e63. doi:10.1016/j.jaac.2014.10.006

13. Goldstein S, Schwebach AJ. The comorbidity of pervasive developmental disorder and attention deficit hyperactivity disorder: results of a retrospective chart review. J Autism Dev Disord. 2004;34:329-339.

14. Ghanizadeh A. Co-morbidity and factor analysis on attention deficit hyperactivity disorder and autism spectrum disorder DSM-IV-derived items. J Res med sci. 2012;17:368-372.

15. Lee DO, Ousley OY. Attention-deficit hyperactivity disorder symptoms in a clinic sample of children and adolescents with pervasive developmental disorders. $J$ Child Adolesc Psychopharmacol. 2006;16:737-746. doi:10.1089/cap.2006.16.737

16. Campbell M, Small AM, Collins PJ, Friedman E, David R, Genieser N. Levodopa and levoamphetamine: a crossover study in young schizophrenic children. Curr Ther Res Clin Exp. 1976;19:70-86. 
17. Aman MG, Pejeau C, Osborne P, Rojahn J, Handen B. Four-year follow-up of children with low intelligence and ADHD. Res Dev Disabil. 1996;17:417-432.

18. Aman MG. Management of hyperactivity and other acting-out problems in patients with autism spectrum disorder. Semin Pediatr Neurol. 2004;11:225-228.

19. Stigler KA, Desmond LA, Posey DJ, Wiegand RE, McDougle CJ. A naturalistic retrospective analysis of psychostimulants in pervasive developmental disorders. $J$ Child Adolesc Psychopharmacol. 2004;14:49-56. doi:10.1089/104454604773840481

20. Nickels KC, Katusic SK, Colligan RC, Weaver AL, Voigt RG, Barbaresi WJ. Stimulant medication treatment of target behaviors in children with autism: a population-based study. J Dev Behav Pediatr. 2008;29:75-81.

21. Posey DJ, Michael GA, Arnold LE et al. Randomized, controlled, crossover trial of methylphenidate in pervasive developmental disorders with hyperactivity. Arch Gen Psychiat. 2005;62:1266-1274. doi:10.1001/ archpsyc.62.11.1266

22. Santosh PJ, Baird G, Pityaratstian N, Tavare E, Gringras P. Impact of comorbid autism spectrum disorders on stimulant response in children with attention deficit hyperactivity disorder: a retrospective and prospective effectiveness study. Child Care Health Dev. 2006;32:575-583. doi:10.1111/j.1365-2214.2006.00631.x

23. Ghanizadeh A, Tordjman S, Jaafari N. Aripiprazole for treating irritability in children \& adolescents with autism: A systematic review. Indian J Med Res. 2015;142:269-275. doi:10.4103/0971-5916.166584

24. Ghanizadeh A, Sahraeizadeh A, Berk M. A head-to-head comparison of aripiprazole and risperidone for safety and treating autistic disorders, a randomized double blind clinical trial. Child Psychiatry Hum Dev. 2014;45:185-192. doi:10.1007/s10578-013-0390-x

25. Ghanizadeh A, Moghimi-Sarani E. A randomized double blind placebo controlled clinical trial of N-Acetylcysteine added to risperidone for treating autistic disorders. BMC Psychiatry. 2013;13:196. doi:10.1186/1471-244x-13-196

26. Ghanizadeh A, Ayoobzadehshirazi A. A randomized double-blind placebo-controlled clinical trial of adjuvant buspirone for irritability in autism. Pediatr Neurol. 2015;52:77-81. doi:10.1016/j. pediatrneurol.2014.09.017

27. Abanilla PK, Hannahs GA, Wechsler R, Silva RR. The use of psychostimulants in pervasive developmental disorders. Psychiat Quart. 2005;76:271-281. doi:10.1007/s11126-005-2980-7

28. Accordino RE, Kidd C, Politte LC, Henry CA, McDougle CJ. Psychopharmacological interventions in autism spectrum disorder. Expert Opin Pharmacother. 2016;17:937-952. doi:10.1517/ 14656566.2016.1154536

29. Aman MG, Farmer CA, Hollway J, Arnold LE. Treatment of inattention, overactivity, and impulsiveness in autism spectrum disorders. Child Adolesc Psychiatr Clin N Am. 2008;17:713-738. doi:10.1016/j. chc.2008.06.009

30. Cauffeld JS. Medication use in autism spectrum disorders: what is the evidence? Formulary. 2013;48:161-168.

31. Posey DJ, McDougle CJ. The pharmacotherapy of target symptoms associated with autistic disorder and other pervasive developmental disorders. Harv Rev Psychiatry. 2000;8:45-63.

32. Davis NO, Kollins SH. Treatment for co-occurring attention deficit/ hyperactivity disorder and autism spectrum disorder. Neurotherapeutics. 2012;9:518-530. doi:10.1007/s13311-012-0126-9

33. Doyle CA, McDougle CJ. Pharmacologic treatments for the behavioral symptoms associated with autism spectrum disorders across the lifespan. Dialogues Clin Neurosci. 2012;14:263-279.
34. Santosh PJ, Singh J. Drug treatment of autism spectrum disorder and its comorbidities in children and adolescents. BJ Psych Adv. 2016;22:151-161. doi:10.1192/apt.bp.115.014597

35. Beherec L, Quilici G, Rosier A, Gerardin P, Campion D, Guillin O. [Pharmacological treatments in patients with pervasive developmental disorders: A review]. L'Encephale. 2014;40:188-196. doi:10.1016/j.encep.2012.01.014

36. Fung LK, Mahajan R, Nozzolillo A, et al. Pharmacologic treatment of severe irritability and problem behaviors in autism: a systematic review and meta-analysis. Pediatrics. 2016;137:S124-S135. doi:10.1542/peds.2015-2851K

37. Benvenuto A, Battan B, Porfirio MC, Curatolo P. Pharmacotherapy of autism spectrum disorders. Brain Dev. 2013;35:119-127. doi:10.1016/j.braindev.2012.03.015

38. Handen BL, Taylor J, Tumuluru R. Psychopharmacological treatment of ADHD symptoms in children with autism spectrum disorder. Int $J$ Adolesc Med Health. 2011;23:167-173. doi:10.1515/ IJAMH.2011.039

39. Blankenship K, Janicak PG. Pharmacotherapy of autism spectrum disorders. Psychopharm Rev. 2011;46:81-88. doi:10.1097/01. PSYPHR.0000407109.91433.4C

40. Kolevzon A. The pharmacologic treatment of attention deficit and hyperactivity in autism. Prim Psychiatry. 2009;16:55-60.

41. Canitano R, Scandurra V. Psychopharmacology in autism: an update. Prog Neuro-Psychopharmacol Biol Psychiatry. 2011;35:18-28. doi:10.1016/j.pnpbp.2010.10.015

42. McCracken JT, Badashova KK, Posey DJ, et al. Positive effects of methylphenidate on hyperactivity are moderated by monoaminergic gene variants in children with autism spectrum disorders. Pharmacogenomics J. 2014;14:295-302. doi:10.1038/tpj.2013.23

43. Posey DJ, Aman MG, McCracken JT, et al. Positive effects of methylphenidate on inattention and hyperactivity in pervasive developmental disorders: an analysis of secondary measures. Biol Psychiat. 2007;61:538-544. doi:10.1016/j.biopsych.2006.09.028

44. Jahromi LB, Kasari CL, McCracken JT, et al. Positive effects of methylphenidate on social communication and self-regulation in children with pervasive developmental disorders and hyperactivity. J Autism Dev Disord. 2009;39:395-404. doi:10.1007/s10803-0080636-9

45. Birmaher B, Quintana H, Greenhill LL. CASE STUDY methylphenidate treatment of hyperactive autistic children. J Am Acad Child Adolesc Psychiatry. 1988;27:248-251. doi:10.1097/00004583198803000-00020

46. Di Martino A, Melis G, Cianchetti C, et al. Methylphenidate for pervasive developmental disorders: safety and efficacy of acute single dose test and ongoing therapy: an open-pilot study. J Child Adolesc Psychopharmacol. 2004;14:207-218. doi:10.1089/104454604164 9011

47. Kim SJ, Shonka S, French WP, Strickland J, Miller L, Stein MA. Dose-Response Effects Of Long-Acting Liquid Methylphenidate In Children With Attention Deficit/Hyperactivity Disorder (ADHD) and Autism Spectrum Disorder (ASD): a pilot study. J Autism Dev Disord. 2017;47:2307-2313. doi:10.1007/s10803-017-3125-1

48. Handen BL, Johnson CR, Lubetsky M. Efficacy of methylphenidate among children with autism and symptoms of attention-deficit hyperactivity disorder. J Autism Dev Disord. 2000;30:245-255.

49. Quintana H, Birmaher B, Stedge D, et al. Use of methylphenidate in the treatment of children with autistic disorder. J Autism Dev Disord. 1995;25:283-294. doi:10.1007/BF02179289 


\section{Publish your work in this journal}

Neuropsychiatric Disease and Treatment is an international, peerreviewed journal of clinical therapeutics and pharmacology focusing on concise rapid reporting of clinical or pre-clinical studies on a range of neuropsychiatric and neurological disorders. This journal is indexed on PubMed Central, the 'PsycINFO' database and CAS, and is the official journal of The International Neuropsychiatric Association (INA). The manuscript management system is completely online and includes a very quick and fair peer-review system, which is all easy to use. Visit http://www.dovepress.com/testimonials.php to read real quotes from published authors.

Submit your manuscript here: https://www.dovepress.com/neuropsychiatric-disease-and-treatment-journal 